\title{
Treatment Modalities for Bleeding Esophagogastric Varices
}

\author{
Hiroshi Yoshida ${ }^{1,2}$, Yasuhiro Mamada ${ }^{1}$, Nobuhiko Taniai ${ }^{1}$, Masato Yoshioka ${ }^{1}$, \\ Atsushi Hirakata ${ }^{1.2}$, Youichi Kawano ${ }^{1}$, Yoshiaki Mizuguchi ${ }^{1}$, Tetsuya Shimizu', \\ Junji Ueda ${ }^{1}$ and Eiji Uchida ${ }^{1}$
}

${ }^{1}$ Surgery for Organ Function and Biological Regulation, Graduate School of Medicine, Nippon Medical School

${ }^{2}$ Department of Surgery, Nippon Medical School Tama Nagayama Hospital

\begin{abstract}
Bleeding from esophageal varices (EVs) or gastric varices (GVs) is a catastrophic complication of chronic liver disease. In this paper, we review the management of bleeding $\mathrm{EVs}$ and GVs.

Diagnosis of EVs and GVs: The grading system for esophagogastric varices proposed by the Japan Society for Portal Hypertension classifies GVs into those involving the cardia (Lg-c), the fundus (Lg-f), and both the cardia and the fundus (Lg-cf). In this review, we divide GVs into 2 categories: Lg-c (cardiac varices: CVs) and Lg-cf or Lg-f (fundal varices: FVs).

Treatment Modalities for EVs and GVs: Treatment modalities for EVs and GVs include placement of a Sengstaken-Blakemore tube, pharmacologic therapy, surgery, interventional radiology, and endoscopic treatment.

Management of Bleeding EVs and GVs: In Japan, endoscopic treatment has recently become the therapy of choice for bleeding EVs or GVs. In other countries, especially the United States, vasoactive drugs and endoscopic treatment are routinely used to manage variceal hemorrhage.

Bleeding EVs: Endoscopic variceal ligation is useful for controlling bleeding from EVs. However, confirmation of ligation precisely at the site of bleeding is usually difficult in patients with massive variceal bleeding. The site of acute bleeding can generally be identified by means of water instillation and suction. Ligation is then performed at the bleeding point. If endoscopic hemostasis is unsuccessful, a Sengstaken-Blakemore tube is used as a temporary bridge to other treatments. Transportal obliteration is useful for blocking variceal blood flow.

Bleeding GVs: Endoscopic injection sclerotherapy with a tissue adhesive, such as N-butylcyanoacrylate or isobutyl-2-cyanoacrylate, is effective for acute bleeding from GVs. However, bleeding from the GV injection site and rebleeding from the rupture point have been reported in patients receiving endoscopic injection sclerotherapy. If endoscopic hemostasis is unsuccessful, a Sengstaken-Blakemore tube is used as a temporary bridge to other treatments. Balloon-occluded retrograde transvenous obliteration and transportal obliteration are useful for the treatment of uncontrolled bleeding from GVs.

Prevention of Recurrent Variceal Hemorrhage: Given the high recurrence rate, survivors of an acute variceal hemorrhage should receive treatment to prevent recurrence. Complete eradication of EVs or GVs and maintenance of low portal venous pressure are essential for preventing recurrence of variceal hemorrhage.
\end{abstract}

(J Nippon Med Sch 2012; 79: 19-30)

Key words: esophageal varices, gastric varices, bleeding, surgery, interventional radiology, embolization, endoscopic treatment

\footnotetext{
Abbreviations: esophageal varices (EVs), gastric varices (GVs), cardiac varices (CVs), fundal varices (FVs), endoscopic injection sclerotherapy (EIS), endoscopic variceal ligation (EVL), interventional radiology (IVR), partial splenic embolization (PSE), distal splenorenal shunt (DSRS), ethanolamine oleate with iopamidol (EOI)

Correspondence to Hiroshi Yoshida, MD, Department of Surgery, Nippon Medical School Tama Nagayama

Hospital, 1-7-1 Nagayama, Tama, Tokyo 206-8512, Japan

E-mail: hiroshiy@nms.ac.jp

Journal Website (http://www.nms.ac.jp/jnms/)
} 


\section{Introduction}

Bleeding from esophageal varices (EVs) or gastric varices (GVs) is a catastrophic complication of chronic liver disease. Bleeding from GVs is generally more severe than that from $\mathrm{EVs}^{1}$ but is less frequent ${ }^{2-4}$. Many years ago, operation was the only treatment available. In the 1970s, techniques for interventional radiology (IVR) were developed and improved the survival rates of patients with bleeding EVs and GVs. In the 1980s, endoscopic treatment further improved survival rates. In this paper, we review the management of bleeding EVs and GVs.

\section{Diagnosis of EVs and GVs}

The grading system for esophagogastric varices proposed by the Japan Society for Portal Hypertension $^{5}$ classifies EVs and GVs on the basis of color (white [Cw] and blue [Cb]), form (small and straight [F1], nodular [F2], and large or coiled [F3]), and red color signs (RC0-3). GVs are divided into those involving the cardia ( $\operatorname{Lg}-\mathrm{c})$, the fundus ( $\mathrm{Lg}-\mathrm{f})$, and both the cardia and the fundus (Lg-cf). In this review, we divide GVs into 2 categories: Lg-c (cardiac varices: CVs) and Lg-cf or Lg-f (fundal varices: FVs).

Bleeding signs are classified into those found during bleeding and those found after hemostasis. Bleeding is classified as gushing, spurting, or oozing. Findings after hemostasis are classified as red plug or white plug.

\section{Treatment Modalities for EVs and GVs}

Treatment modalities for EVs and GVs include placement of a Sengstaken-Blakemore (SB) tube, pharmacologic therapy, surgery, IVR, and endoscopic treatment.

\section{The SB Tube}

The SB tube, first described in $1950 \mathrm{~s}^{6}$, is a multiluminal plastic tube with 2 inflatable balloons. The proximal balloon is used to arrest bleeding by directly compressing EVs. The distal balloon compresses the feeding veins of the EV. The effectiveness of balloon tamponade with the SB tube is reported to be $90 \%{ }^{6}$. Aspiration of secretions is the most common complication of balloon tamponade, occurring in $10 \%$ to $20 \%$ of cases $^{7}$. Esophageal rupture and acute upper airway obstruction are rare fatal complications of treating bleeding EVs or GVs with an $\mathrm{SB}$ tube $\mathrm{s}^{8-11}$. Currently, balloon tamponade is only used as a temporary bridge to other strategies when other hemostatic treatments are unsuccessful. Balloon tamponade is more effective in patients with less severe hepatic dysfunction. Previous endoscopic therapy may increase the effectiveness of tamponade without increasing the risk of esophageal perforation $^{12}$.

\section{Pharmacologic Therapy}

Splanchnic vasoconstrictors, such as vasopressin and somatostatin (and their analogues octreotide and vapreotide), are administered parenterally and used only in an acute care setting. Pharmacologic therapy has 2 major advantages: it is generally applicable and can be started as soon as variceal hemorrhage is suspected. A recent meta-analysis of 15 trials comparing emergency sclerotherapy and pharmacologic treatment (vasopressin, nitroglycerin, terlipressin, somatostatin, or octreotide) showed similar efficacy, with fewer side effects for pharmacologic therapy. Pharmacologic therapy is considered the first-line treatment for variceal bleeding $^{13}$.

\section{Surgery}

Many years ago, surgery was only treatment for bleeding EVs or GVs. Several surgical procedures have been developed to manage EVs and GVs. They can be broadly classified as shunting procedures and nonshunting procedures ${ }^{14}$.

Shunting procedures: The goal of shunting is to reduce the incidence of variceal bleeding by lowering the pressure in the portal system by means of a portosystemic shunt. A standard portocaval shunt effectively reduces the incidence of variceal bleeding; however, impaired metabolism of hepatic proteins after shunting frequently causes hepatic encephalopathy due to hyperammonemia ${ }^{15-17}$. In 1967 Warren et al. developed the distal 
splenorenal shunt (DSRS) to preserve portal blood flow through the liver while lowering variceal pressure $^{18}$. This approach was developed in the hope of preventing bleeding as well as hyperammonemia. Despite initial expectations, DSRS has been found to effectively prevent rebleeding but not to eliminate the risk of hyperammonemia. To solve this problem, our group designed a DSRS with splenopancreatic disconnection and gastric transection, modifications to prevent the loss of shunt selectivity. Our modified DSRS has been confirmed to reduce the incidence of postoperative hyperammonemia ${ }^{19}$.

Nonshunting procedures: As an alternative to shunting, Hassab ${ }^{20}$ and Sugiura and Futagawa ${ }^{21}$ developed techniques for gastroesophageal decongestion and splenectomy to manage varices. The Hassab operation devascularizes the distal esophagus and proximal stomach. Splenectomy, selective vagotomy, and pyloroplasty can be performed concomitantly with the procedure. Sugiura and Futagawa ${ }^{21}$ developed a procedure for esophageal transection in patients with EVs and GVs. While the procedures of Hassab and of Sugiura and Futagawa solve the problem of hepatic encephalopathy, varices are likely to recur earlier after these procedures than after DSRS ${ }^{22}$.

\section{IVR}

In the 1970s, IVR techniques were developed for the treatment of EVs and GVs. Before IVR is performed, portal hemodynamics should be evaluated. Angiography can be used to assess the hemodynamics of varices during embolization.

Transportal obliteration: Two methods have been used to obliterate the feeding veins of EVs or GVs: percutaneous transhepatic obliteration and transileocolic vein obliteration. These procedures are performed in similar ways. A catheter is inserted directly into the portal vein, and the portal circulation is visualized with portography. A balloon catheter is inserted selectively into the inflow site of the feeding veins of the varices. The balloon is inflated, and a test dose of contrast medium is injected to determine the optimal volume of sclerosant. Five percent ethanolamine oleate iopamidol (EOI), $50 \%$ glucose, or both are injected to obliterate the feeding vein(s). Steel coils are then used to complete obliteration ${ }^{23}$.

Balloon-occluded retrograde transvenous obliteration: Balloon-occluded retrograde transvenous obliteration (B-RTO) is a notable IVR procedure developed especially for the treatment of FVs. This treatment is performed by inserting a balloon catheter into the outflow shunt (gastric-renal shunt or gastric-inferior phrenic vein shunt) via the femoral or internal jugular vein. Any existing collateral veins are treated with coils, absolute ethanol, or a small amount of 5\% EOI. The balloon is inflated, and a test dose of contrast medium is injected to determine the optimal volume of the sclerosant. Five percent EOI is slowly injected through the catheter until the shunt is filled with the sclerosant. The catheter is removed after 24 hours of balloon occlusion ${ }^{24-26}$. A high rate of $\mathrm{FV}$ eradication or shrinkage can be expected if the B-RTO procedure is technically successful ${ }^{27}$. Indeed, long-term eradication of treated FVs without recurrence is achieved in most patients $^{24,28}$. Kanagawa et al. $^{24}$ confirmed eradication of FVs in 31 of 32 patients treated with B-RTO, and no FVs recurred in any patient within a mean follow-up period of 14 months. In earlier studies, the eradication rate of FVs exceeded $89 \%$, and the recurrence rate was less then $7 \%$. Given the minimal invasiveness and high safety of the procedure, BRTO can be performed on either an elective or emergency basis to treat FVs.

Partial splenic embolization: Partial splenic embolization (PSE) has been used to treat hypersplenism, EVs, GVs, portal hypertensive gastropathy, pancreatic carcinoma, splenic aneurysm, and portal-systemic encephalopathy $y^{23,29-41}$.

The femoral artery approach is used for superselective catheterization of the splenic artery. The tip of a catheter is placed as distally as possible in either the hilus of the spleen or in an intrasplenic artery. Embolization is achieved by injecting 2-mm gelatin-sponge cubes suspended in a saline solution containing antibiotics ${ }^{33,34,42}$. As with transportal obliteration, complete disappearance of EVs or GVs is difficult to achieve with PSE alone. PSE is thus a supplemental treatment for EVs or GVs.

Transjugular intrahepatic portosystemic shunt: 
Placement of a transjugular intrahepatic portosystemic shunt (TIPS) is currently considered a salvage therapy for the $10 \%$ to $20 \%$ of patients in whom standard medical therapy fails. However, 2 randomized, controlled trials have shown that early placement of such a shunt (within 24 to 48 hours after admission) is associated with significantly improved survival among high-risk patients (i.e., patients with a hepatic venous pressure gradient of $>20 \mathrm{~mm} \mathrm{Hg}^{43}$ or with Child class $\mathrm{C}$ disease with a score of 10 to 13 points ${ }^{44}$ ). Therefore, early placement of a TIPS is a treatment option in such patients. Although the potential benefits and risks of TIPS placement require further investigation, the decision to use this approach as salvage therapy in this subgroup of high-risk patients should be made sooner rather than later.

Transportal obliteration and B-RTO are techniques for embolization of the collateral veins of the portal system due to portal hypertension. PSE reduces inflow of the portal system. TIPS increases outflow of the portal system. The IVR techniques of PSE and TIPS both reduce portal pressure.

\section{Endoscopic Treatment}

Two endoscopic techniques are used to treat EVs or GVs: endoscopic injection sclerotherapy (EIS) and endoscopic variceal ligation $(\mathrm{EVL})^{45-51}$.

EIS: EIS can be accomplished with either intravariceal EIS or extravariceal EIS ${ }^{46-48.52}$. First, the endoscope is introduced. Then, a flexible endoscopic sheath is positioned to permit reinsertion of the endoscope and prevent aspiration.

1) Intravariceal EIS: An anal-side balloon is inserted into the stomach, and a 22-gauge needle is inserted into the target $\mathrm{EV} 2$ to $3 \mathrm{~cm}$ proximal to the gastroesophageal junction. The sclerosant $(5 \%$ $\mathrm{EOI}$ ) is infused into the $\mathrm{EV}$, and flow is monitored with fluoroscopy to confirm filling of the feeder vessel or the pericardiac venous plexus. Suction is maintained at the puncture point while the needle remains in the EVs. The same procedure is then repeated for other variceal columns in the lower esophagus. After injection has been completed, the injection site is compressed by inflating the anal-side balloon with air.
In the treatment of EVs, intravariceal EIS obliterates both the interconnecting perforating veins and the feeding veins of EVs. Nearby, however, some dilated winding cardiac veins might transverse the submucosa and directly join the EVs. This relationship allows most CVs to be treated concomitantly with EVs when the latter are being corrected with intravariceal EIS. Intravariceal EIS is useful for obliterating feeding veins of recurrent EVs after operation ${ }^{48}$. However, EIS has high incidences of local and systemic complications ${ }^{53}$.

Traditional EIS with 1\% polidocanol, 5\% EOI, or thrombin has been less successful and is associated with a high mortality rate in patients with GVs, especially $\mathrm{FVs}^{1,54-57}$. These outcomes are attributed to GVs being associated with a gastrorenal shunt or a gastric-inferior vena caval shunt, resulting in outflow into the systemic circulation ${ }^{24}$. These anatomic characteristics of a major portosystemic shunt create a higher blood flow volume through the shunt, with resultant rapid escape of sclerosant into the systemic circulation during EIS. Consequently, conventional EIS does not allow the sclerosing agent to start thrombosis on the surface endothelium of the GVs. Furthermore, there is a risk of serious complications. For example, the sclerosant can cause pulmonary embolism via the major shunt, and massive ulcer bleeding can be induced through the puncture of large $\mathrm{GVs}^{58}$.

2) Extravariceal EIS: Extravariceal EIS is performed with $1 \%$ polidocanol to treat remaining varices by paravariceal injection ${ }^{59}$. The end point of primary treatment is the complete eradication of any residual varices between the ulcers created by extravariceal EIS during the first hospitalization. Extravariceal EIS achieves local eradication but does not completely disrupt the interconnecting perforating and feeder vessels ${ }^{60}$.

Post-EIS management is as follows: (1) after 6 to 8 hours of fasting, liquid food is permitted; (2) administration of antibiotics to prevent infection; (3) use of medication to lower portal vein pressure as required; and (4) close monitoring the patient for signs of complications, such as bleeding, perforation, fever, sepsis, and embolization of distant vascular beds. 


\section{EVL}

EVL is increasingly used because of its safety and simplicity and because no sclerosant is required ${ }^{45}$. EVL achieves local eradication, but does not completely disrupt interconnecting perforating and feeder vessels ${ }^{60}$. Nevertheless, early recurrence of EVs after EVL has been reported ${ }^{46}$.

The endoscope is introduced with a flexible endoscopic sheath. The endoscope is then removed and attached to a pneumatically activated EVL device (Sumitomo Bakelite, Tokyo, Japan). The endoscope is reinserted, and suction on the varix is maintained. As the varix is pulled into the ligator cap, air is injected into the tube to accomplish the EVL. At the first treatment session, all varices are ligated from the gastroesophageal junction to the oral side. Each varix is ligated with 1 to 2 bands. During the second and third sessions, the remaining varices undergo $\mathrm{EVL}^{50}$.

Post-EVL management: After the operation, the patient should fast for 24 hours and be closely observed for complications, such as hemorrhage (bleeding caused by the incision of bands), sloughing off of the bands (early recurrence of hemorrhage), fever, and a local choking sensation. Prophylactic antibiotics are given to all patients for 3 days. The antibiotic dosage is then adjusted on the basis of the results of sensitivity testing in patients confirmed to have an infection.

Combination of EIS and EVL: Several investigators have examined the efficacy of EVL combined with EIS for the treatment of $\mathrm{EVs}^{61-63}$. Saeed et ll. $^{61}$ and Laine et al. $^{62}$ have compared a single session of treatment with EVL plus lowvolume EIS with a single session of EVL alone and concluded that EVL alone is superior to combination therapy. EVL was performed first, followed by intravariceal EIS immediately proximal to the ligature. The main limitation of this method is that only half of the feeding vessels are treated because the sclerosant is injected into the $\mathrm{EV}$ proximal to the ligature; distal vessels, therefore, do not undergo sclerosis.

EVL followed by EIS differs fundamentally from
EIS followed by EVL. Moreover, the combination of intravariceal EIS and EVL differs from that of extravariceal EIS and EVL. EVL and extravariceal EIS both eradicate varices locally, with no effect on interconnecting perforating or feeding vessels ${ }^{60}$. Takase et al. $^{64}$ have concluded that feeder vessels must be obliterated to prevent recurrence.

We have developed a new technique combining EVL with EIS called endoscopic scleroligation (ESL). In this technique, intravariceal EIS is performed before ligation. The puncture needle is removed after sclerosant infusion, and EVL, including the placement of bands at the injection site, is performed simultaneously. The same procedure is repeated for other EVs around the lower esophagus. Additional sclerosant is not injected. Intensive EVL is performed for EVs in the lower to middle esophagus $^{46}$.

New methods for the management of EVsBimonthly EVL: EVL and extravariceal EIS are not always effective, and early recurrences have been reported ${ }^{46}$. Furthermore, most patients with endoscopically treated EVs require follow-up therapy for recurrent varices. Proper management of recurrent EVs can significantly improve patients' quality of life.

We conventionally perform EVL treatment once every 2 weeks (biweekly). We compared the shortand long-term results of EVL performed in 3 sessions with a total of 16 O-rings at 2 different intervals, i.e., biweekly (conventional interval) and bimonthly. The overall rates of variceal recurrence and additional treatment were both higher after biweekly EVL than after bimonthly EVL $(P<0.001)$. We concluded that EVL once every 2 months (bimonthly) produces better outcomes than EVL once every 2 weeks (biweekly) in patients with EVs. Treatment sessions separated by a longer interval had a higher rate of total eradication and lower rates of recurrence and additional treatment ${ }^{50}$.

\section{Combination of Endoscopic Treatment and IVR}

Treatment of GVs solely with endoscopic modalities or with IVR is occasionally inadequate. Our group has previously reported that treatment combining IVR and endoscopic modalities has 
significant effects on long-term rebleeding and retreatment rates in patients with $\mathrm{EVs}$ or $\mathrm{GVs}^{23,35,37,38}$. Cumulative retreatment rates in patients with Child's class C disease are lower after endoscopic treatment plus IVR than after endoscopic treatment alone $(P=0.025)$. The combination of endoscopic therapy and IVR was shown to be effective for EVs, especially in patients with poor liver function ${ }^{23}$. In patients who undergo elective therapy, complete GV treatment should be performed to minimize the risk of rebleeding. The combination of IVR and endoscopic therapy is highly effective and provides an alternative to surgery in patients with EVs or $\mathrm{GVS}^{30,65}$

\section{Management of Bleeding EVs and GVs}

Endoscopic treatment has recently become the treatment of choice for bleeding EVs or GVs in $\mathrm{Japan}^{65.66}$. In other countries, especially the United States, vasoactive agents and endoscopic treatment are routinely used to manage variceal hemorrhage.

\section{Management before Endoscopic Examination}

The management of variceal hemorrhage relies on adequate fluid resuscitation, blood volume resuscitation, airway protection, prophylactic antibiotics, and antiulcer drugs. Treatment strategies for early-stage, moderate, and severe bleeding include correction of hypovolemic shock, stopping hemorrhage, prevention of complications due to gastrointestinal hemorrhage, and monitoring vital signs and urine volume.

Both $\mathrm{H}_{2}$-receptor antagonists and proton-pump inhibitors can increase the $\mathrm{pH}$ of the stomach, stimulate the aggregation of platelets and the formation of fibrin clots, and prevent or dissolve early blood clots. These agents are, therefore, beneficial for stopping bleeding and preventing rebleeding ${ }^{67}$.

Inflammation and edema of gastric and esophageal mucous membranes commonly develop during active bleeding. Prophylactic use of antibiotics is helpful for controlling active hemorrhage and may decrease the incidence of early rebleeding and prevent infection. A meta-analysis has suggested that the use of antibiotics increases survival rates by decreasing rebleeding and infection ${ }^{68}$. Therefore, short-term treatment with prophylactic antibiotics should be considered in all patients with cirrhosis and acute variceal hemorrhage.

\section{Endoscopic Examination}

After premedication with an intramuscular injection of scopolamine butylbromide $(20 \mathrm{mg})$ and an intravenous injections of atropine sulfate $(0.25$ $\mathrm{mg})$, pentazocine $(15 \mathrm{mg})$, hydroxyzine $(25 \mathrm{mg})$, and diazepam (5 mg), a 1-channel endoscope is introduced. A flexible endoscopic sheath is then inserted. Endoscopic examination is performed to check for active bleeding sites or plugs. Bleeding signs are classified according to those found during bleeding and those found after hemostasis. Bleeding is classified as gushing, spurting, or oozing, and findings after hemostasis are classified as red plug or white plug.

If massive coagula preclude examination of the bleeding site, the endoscope is removed, the flexible endoscopic sheath is left in place, and the patient's position is changed from the full left-lateral position to the right-lateral position. As a result, the massive coagula move from the fundus to the antrum. Furthermore, hemostasis of GVs is occasionally achieved because the bleeding site is elevated when the patient is placed in the right-lateral position.

\section{Bleeding EVs (Fig. 1)}

EVL is useful for controlling bleeding from EVs. However, confirming ligation precisely at the site of bleeding is usually difficult when treating massive variceal bleeding. For patients with acute bleeding, the bleeding point is identified by instilling water and applying suction. Ligation is then performed at the bleeding point. Subsequently, each varix is ligated with 1 or 2 bands.

Matsutani et al. have reported that after EVL of the bleeding site of an EV, an unusual white ball-like appearance (white ball appearance) is noted. This finding differs markedly from the purple ball-like appearance that is usually observed after EVL of an 


\section{Bleeding esophageal varices}

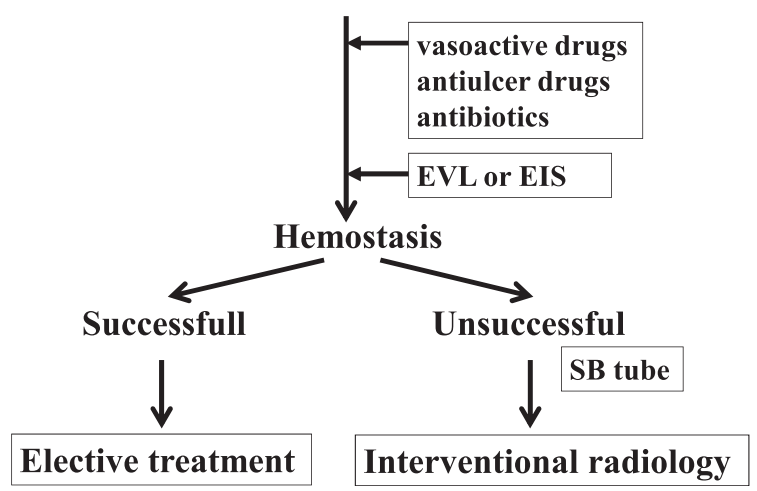

Fig. 1 Treatment of bleeding esophageal varices

$\mathrm{EV}$ at a site without bleeding. This finding is useful for confirming the successful EVL of an EV at its bleeding site ${ }^{69}$.

Intravariceal EIS is also useful for controlling bleeding from EVs. The sclerosant (5\% EOI) is infused near the bleeding site of $\mathrm{EV}$ under fluoroscopic guidance to confirm filling of the feeder vessel or the pericardiac venous plexus.

As for the best endoscopic therapy, a metaanalysis of 10 randomized controlled trials including 404 patients showed a nearly significant benefit of EVL as compared with EIS for the initial control of bleeding (pooled relative risk, 0.53; 95\% confidence interval, $0.28-1.01)^{70}$.

If endoscopic hemostasis is unsuccessful, balloon tamponade with an SB tube is used as a temporary bridge to other treatments. Transportal obliteration is useful for blocking variceal blood flow.

Narahara et $\mathrm{al}^{71}$ have compared the efficacy of TIPS with that of EIS in the long-term management of bleeding from EVs in patients with cirrhosis. They found no significant differences between the treatment groups in rebleeding from any source or in rebleeding from EVs. The mortality rates were similar in both treatment groups. Shunt dysfunction occurred in $71 \%$ of the patients in the TIPS group. During follow-up, rehospitalization was more frequent in the TIPS group ( $2.6 \pm 0.4$ cases $)$ than in the EIS group $(1.1 \pm 0.2$ cases; $\mathrm{P}<0.01)$. TIPS and EIS were equally effective for preventing rebleeding from EVs. However, TIPS was associated with a high incidence of shunt dysfunction, leading to more rehospitalizations. Therefore, TIPS may not be
Bleeding gastric varices

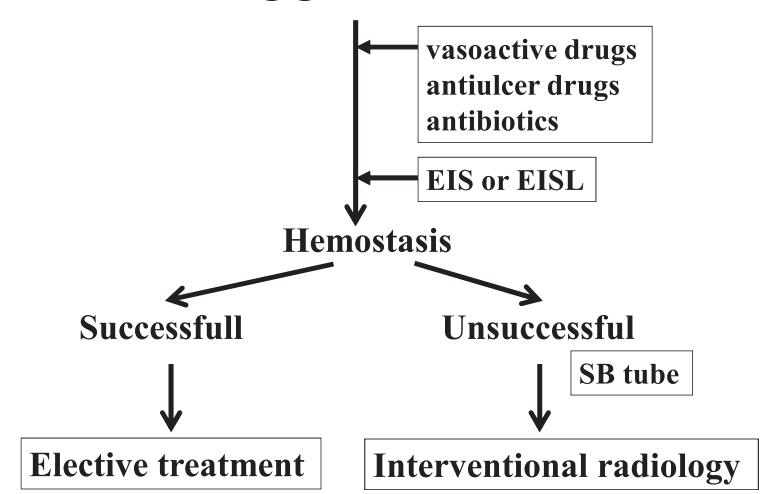

Fig. 2 Treatment of bleeding gastric varices

suitable as a first-line treatment for preventing rebleeding from EVs in patients with cirrhosis who are in stable condition.

\section{Bleeding GVs (Fig. 2)}

As compared with EIS or EVL, endoscopic variceal obturation with EIS and a tissue adhesive, such as N-butyl-cyanoacrylate (Histoacryl, TissueSeal LLC, Ann Arbor, MI, USA) or isobutyl-2cyanoacrylate, is more effective for acute bleeding from FVs. The advantages of EIS include a better rate of controlling the initial hemorrhage ${ }^{72-78}$. However, bleeding from the GV injection site and rebleeding from rupture points have been reported in patients $\mathrm{EIS}^{2,57}$.

While Although EVL is generally safe and effective for the treatment of $\mathrm{CVs}$ and $\mathrm{FVs}^{79}$, it sometimes causes deep or extensive ulcers and increases the risk of ensuing ulcer hemorrhage or secondary bleeding ${ }^{80}$. FVs are usually 2 to 3 times as large as EVs and are directly connected to an extremely dilated left gastric or posterior gastric vein $^{81}$. The volume of blood flow through an $\mathrm{FV}$, therefore, usually exceeds that through an $\mathrm{EV}^{82}$. A mucosal injury remains on varices after endoscopic treatment. If blood flow in the varices cannot be stopped completely, bleeding may recur at the site of this mucosal injury. This possibility of rebleeding underlines the importance of ensuring the complete obliteration of blood flow when treating FVs endoscopically.

An international consensus meeting at the Baveno 
IV workshop in 2005 recommended that a tissue adhesive, such as a cyanoacrylate, is the only agent that should be used to control bleeding from $\mathrm{FVs}^{83}$. Prospective randomized controlled studies have recently examined the management of bleeding from $\mathrm{GVS}^{84-87}$. However, comparing results among different studies remains difficult because various types of GVs have been included, with no clear explanation or classification of the varices.

GVs have also been treated with a endoscopic technique combining the use of a detachable snare with simultaneous EIS and O-ring ligation ${ }^{88}$. This technique is not yet in widespread use, however. Our group has reported on the treatment of ruptured GVs by means of EIS with N-butylcyanoacrylate followed by O-ring ligation (endoscopic scleroligation [EISL]) ${ }^{49}$. EISL was developed as a treatment for EVs to prevent bleeding from the injection site during needle removal ${ }^{46,89}$. When treating GVs by means of EIS with N-butylcyanoacrylate, immediate freezing of the N-butylcyanoacrylate around the needle hinders its removal after injection. In some patients, bleeding from the $\mathrm{GV}$ injection site or rebleeding from the rupture point also occurs ${ }^{2,57}$. Our group has used EISL to treat bleeding from GVs with punctures near the bleeding point by simultaneously ligating the injection site and the bleeding point. EISL effectively stops bleeding from GVs, enables swift and easy needle removal, and successfully eliminates both bleeding from the injection site and rebleeding from the bleeding point. An O-ring is placed at the point of EISL injection with N-butyl-cyanoacrylate and is left in place for a prolonged time. As of this writing, EISL with N-butyl-cyanoacrylate is considered the most promising treatment for bleeding from GVs.

If endoscopic hemostasis is unsuccessful, balloon tamponade with an SB tube is used as a temporary bridge to other treatments. B-RTO or transportal obliteration is useful for treating uncontrolled bleeding from GVs.

Some studies have suggested that B-RTO is effective for the secondary prophylaxis of bleeding GVs. The long-term rate of rebleeding from FVs was reported to be much lower after B-RTO than after previous endoscopic treatments with a cyanoacrylate. Most studies have shown that prophylactic treatment with B-RTO effectively prevents bleeding of large GVs without a history of bleeding, and a 100\% nonbleeding rate has been reported after long-term follow-up ${ }^{28,90-92}$. The treatment of FVs with B-RTO has 2 important effects: eradication of the FVs themselves and obliteration of the unified portosystemic shunt. Most of the benefits and adverse effects of B-RTO are related to the latter effect. Such benefits as decreased blood ammonia levels and improvement in portosystemic encephalopathy are sometimes observed. Possible adverse effects include transient ascites, worsening ascites, pleural effusion, and the appearance of EVs manifesting red color signs. These adverse effects may be caused by elevated portal pressure due to occlusion of the portosystemic shunt.

Transportal obliteration is also effective for the treatment of GVs, because the feeding veins of GVs are obliterated. The procedure is highly effective, although the rate of complete disappearance of GVs is not so high after transportal obliteration alone. BRTO combined with transportal obliteration is more useful for the treatment of GVs.

Collateral veins, including feeding veins of GVs, decrease portal hypertension. Obliteration of collateral veins by such procedures as B-RTO and transportal obliteration thus increases portal congestion and portal pressure, especially in patients with cirrhosis. PSE has been performed incrementally to reduce portal venous pressure to the level it was before the obliteration of collateral veins $^{23,30,33,36,37,42,47,93,94}$.

Several studies have demonstrated the value of TIPS for uncontrolled bleeding from GVs. Bleeding control rates exceeding 90\% have been obtained. Although bleeding from GVs has been suggested to be more difficult to control with TIPS than is bleeding from EVs, a prospective study comparing salvage TIPS for uncontrolled bleeding from FVs with that from EVs showed equal efficacy for both types of varix, with control of hemorrhage in all but 1 patient with each type of varix ${ }^{95}$.

A comparison of DSRS and TIPS has found no significant difference in the rate of rebleeding or the 
rate of the first encephalopathy event. Rates of thrombosis, stenosis, and reintervention were significantly higher with TIPS $^{96}$, although TIPS may be more cost effective ${ }^{97}$.

The threshold for the placement of TIPS to control bleeding is lower for GVs than for EVs. TIPS can be recommended if endoscopic therapy is not possible or after a single failure to respond to endoscopic treatment.

\section{Prevention of Recurrent Variceal Hemorrhage}

Given the high recurrence rate, patients who survive an acute variceal hemorrhage should undergo treatment to prevent recurrence. Complete eradication of EVs or GVs and maintenance of low portal venous pressure are essential for the prevention of recurrent variceal hemorrhage.

\section{References}

1. Trudeau W, Prindiville T: Endoscopic injection sclerosis in bleeding gastric varices. Gastrointest Endosc 1986; 32: 264-268.

2. Sarin SK, Lahoti D, Saxena SP, Murthy NS, Makwana UK: Prevalence, classification and natural history of gastric varices: a long-term follow-up study in 568 portal hypertension patients. Hepatology 1992; 16: 1343-1349.

3. Hashizume M, Kitano S, Yamaga H, Koyanagi N, Sugimachi K: Endoscopic classification of gastric varices. Gastrointest Endosc 1990; 36: 276-280.

4. Tajiri T, Onda M, Yoshida H, Mamada Y, Taniai N, Yamashita K: The natural history of gastric varices. Hepatogastroenterology 2002; 49: 1180-1182.

5. Tajiri T, Yoshida H, Obara K, et al.: General rules for recording endoscopic findings of esophagogastric varices (2nd edition). Dig Endosc 2010; 22: 1-9.

6. Sengstaken RW, Blakemore AH: Balloon tamponage for the control of hemorrhage from esophageal varices. Ann Surg 1950; 131: 781-789.

7. Avgerinos A, Armonis A: Balloon tamponade technique and efficacy in variceal haemorrhage. Scand J Gastroenterol Suppl 1994; 207: 11-16.

8. Hamm DD, Papp JP: Rupture of esophagus during use of Sengstaken-Blakemore tube. Postgrad Med 1974; 56: 199-200.

9. Zeid SS, Young PC, Reeves JT: Rupture of the esophagus after introduction of the SengstakenBlakemore tube. Gastroenterology 1959; 36: 128-131.

10. Lin CT, Huang TW, Lee SC, et al.: SengstakenBlakemore tube related esophageal rupture. Rev Esp Enferm Dig 2010; 102: 395-396.

11. Chong CF: Esophageal rupture due to SengstakenBlakemore tube misplacement. World J Gastroenterol 2005; 11: 6563-6565.

12. Pinto-Marques $\mathrm{P}$, Romaozinho JM, Ferreira M,
Amaro P, Freitas D: Esophageal perforationassociated risk with balloon tamponade after endoscopic therapy. Myth or reality? Hepatogastroenterology 2006; 53: 536-539.

13. D’Amico G, Pietrosi G, Tarantino I, Pagliaro L: Emergency sclerotherapy versus vasoactive drugs for variceal bleeding in cirrhosis: a Cochrane metaanalysis. Gastroenterology 2003; 124: 1277-1291.

14. Yoshida H, Mamada Y, Taniai N, Tajiri T: New trends in surgical treatment for portal hypertension. Hepatol Res 2009; 39: 1044-1051.

15. Millikan WJ Jr, Warren WD, Henderson JM, et al: The Emory prospective randomized trial: selective versus nonselective shunt to control variceal bleeding. Ten year follow-up. Ann Surg 1985; 201: $712-722$.

16. Rikkers LF, Jin G: Variceal hemorrhage: surgical therapy. Gastroenterol Clin North Am 1993; 22: 821842.

17. Rikkers LF, Sorrell WT, Jin G: Which portosystemic shunt is best? Gastroenterol Clin North Am 1992; 21: 179-196.

18. Warren WD, Zeppa R, Fomon JJ: Selective transsplenic decompression of gastroesophageal varices by distal splenorenal shunt. Ann Surg 1967; 166: 437455.

19. Tajiri $\mathrm{T}$, Onda $\mathrm{M}$, Yoshida $\mathrm{H}$, et al.: Long-term results of modified distal splenorenal shunts for the treatment of esophageal varices. Hepatogastroenterology 2000; 47: 720-723.

20. Hassab MA: Gastroesophageal decongestion and splenectomy in the treatment of esophageal varices in bilharzial cirrhosis: further studies with a report on 355 operations. Surgery 1967; 61: 169-176.

21. Sugiura M, Futagawa S: A new technique for treating esophageal varices. J Thorac Cardiovasc Surg 1973; 66: 677-685.

22. Tajiri T, Onda M, Yoshida H, Mamada Y, Taniai N, Yamashita K: Comparison of the long-term results of distal splenorenal shunt and esophageal transection for the treatment of esophageal varices. Hepatogastroenterology 2000; 47: 1619-1621.

23. Taniai N, Onda M, Tajiri T, Yoshida H, Mamada Y: Combined endoscopic and radiologic intervention to treat esophageal varices. Hepatogastroenterology 2002; 49: 984-988.

24. Kanagawa H, Mima S, Kouyama H, Gotoh K, Uchida T, Okuda K: Treatment of gastric fundal varices by balloon-occluded retrograde transvenous obliteration. J Gastroenterol Hepatol 1996; 11: 51-58.

25. Hirota S, Matsumoto S, Tomita M, Sako M, Kono M: Retrograde transvenous obliteration of gastric varices. Radiology 1999; 211: 349-356.

26. Chikamori F, Shibuya S, Takase Y, Ozaki A, Fukao $\mathrm{K}$ : Transjugular retrograde obliteration for gastric varices. Abdom Imaging 1996; 21: 299-303.

27. Takahashi T, Yoshida H, Mamada Y, Taniai N, Tajiri $\mathrm{T}$ : Balloon-occluded retrograde transvenous obliteration for gastric varices in a child with extrahepatic portal venous obstruction. J Nippon Med Sch 2009; 76: 173-178.

28. Fukuda T, Hirota S, Sugimura K: Long-term results of balloon-occluded retrograde transvenous obliteration for the treatment of gastric varices and hepatic encephalopathy. J Vasc Interv Radiol 2001; 
12: $327-336$.

29. Shimizu T, Onda M, Tajiri T, et al: Bleeding portalhypertensive gastropathy managed successfully by partial splenic embolization. Hepatogastroenterology 2002; 49: 947-949.

30. Tajiri T, Onda M, Taniai N, Yoshida H, Mamada Y: A comparison of combination endoscopic therapy and interventional radiology with esophageal transection for the treatment of esophageal varices. Hepatogastroenterology 2002; 49: 1552-1554.

31. Yoshida H, Onda M, Tajiri T, et al.: New techniques: splenic artery embolization followed by intraarterial infusion chemotherapy for the treatment of pancreatic cancer. Hepatogastroenterology 1999; 46: 2024-2027.

32. Yoshida H, Onda M, Tajiri T, et al.: Experience with intraarterial infusion of styrene maleic acid neocarzinostatin(SMANCS)-lipiodol in pancreatic cancer. Hepatogastroenterology 1999; 46: 2612-2615.

33. Yoshida H, Mamada Y, Taniai N, et al.: Long-term results of partial splenic artery embolization as supplemental treatment for portal-systemic encephalopathy. Am J Gastroenterol 2005; 100: 43-47.

34. Yoshida H, Mamada Y, Taniai N, Tajiri T: Partial splenic embolization. Hepatol Res 2008; 38: 225-233.

35. Taniai N, Onda M, Tajiri T, Toba M, Yoshida H: Endoscopic variceal ligation (EVL) combined with partial splenic embolization (PSE). Hepatogastroenterology 1999; 46: 2849-2853.

36. Taniai N, Onda M, Tajiri T, Yoshida H, Mamada Y: Interventional radiology and endoscopic therapy for recurrent esophageal varices. Hepatogastroenterology 2001; 48: 133-136.

37. Yoshioka M, Onda M, Tajiri T, et al: Control of isolated gastric varices by combination therapy using embolization and endoscopic scleroligation therapy. Hepatogastroenterology 2002; 49: 955-957.

38. Taniai N, Yoshida H, Mamada Y, Tajiri T: The treatment of gastric fundal varices-endoscopic therapy versus interventional radiology. Hepatogastroenterology 2005; 52: 949-953.

39. Takahashi T, Arima Y, Yokomuro S, et al.: Splenic artery embolization before laparoscopic splenectomy in children. Surg Endosc 2005; 19: 1345-1348.

40. Shimizu T, Tajiri T, Yoshida H, et al.: Hand-assisted laparoscopic hepatectomy after partial splenic embolization. Surg Endosc 2003; 17: 1676.

41. Hara K, Yoshida H, Taniai N, Mineta S, Kawano Y, Uchida E: Successful management of a symptomatic splenic artery aneurysm with transcatheter embolization. J Nippon Med Sch 2009; 76: 308-318.

42. Tajiri T, Onda M, Yoshida H, Mamada Y, Taniai N, Kumazaki T: Long-term hematological and biochemical effects of partial splenic embolization in hepatic cirrhosis. Hepatogastroenterology 2002; 49: 1445-1448.

43. Monescillo A, Martinez-Lagares F, Ruiz-del-Arbol L, et al: Influence of portal hypertension and its early decompression by TIPS placement on the outcome of variceal bleeding. Hepatology 2004; 40: 793-801.

44. Garcia-Pagan JC, Caca K, Bureau C, et al.: Early use of TIPS in patients with cirrhosis and variceal bleeding. N Engl J Med 2010; 362: 2370-2379.

45. Masumori K, Onda M, Tajiri T, et al.: Modified endoscopic variceal ligation. Dig Endosc 1995; 7: 165-
170.

46. Umehara M, Onda M, Tajiri T, Toba M, Yoshida H, Yamashita K: Sclerotherapy plus ligation versus ligation for the treatment of esophageal varices: a prospective randomized study. Gastrointest Endosc 1999; 50: 7-12.

47. Tajiri T, Onda M, Yoshida H, et al.: Endoscopic scleroligation is a superior new technique for preventing recurrence of esophageal varices. J Nippon Med Sch 2002; 69: 160-164.

48. Yoshida H, Onda M, Tajiri T, et al.: Endoscopic injection sclerotherapy for the treatment of reccurent esophageal varices after esophageal transection. Dig Endosc 2002; 14: 93-98.

49. Yoshida H, Onda M, Tajiri T, et al.: New techniques: combined endoscopic injection sclerotherapy and ligation for acute bleeding from gastric varices. Hepatogastroenterology 2002; 49: 932-934.

50. Yoshida H, Mamada Y, Taniai N, et al.: A randomized control trial of bi-monthly versus biweekly endoscopic variceal ligation of esophageal varices. Am J Gastroenterol 2005; 100: 2005-2009.

51. Sarin SK, Govil A, Jain AK, et al.: Prospective randomized trial of endoscopic sclerotherapy versus variceal band ligation for esophageal varices: influence on gastropathy, gastric varices and variceal recurrence. J Hepatol 1997; 26: 826-832.

52. Yoshida H, Tajiri T, Mamada Y, et al.: Comparison of characteristics of recurrent esophageal varices after endoscopic ligation versus endoscopic ligation plus sclerotherapy. Hepatogastroenterology 2004; 51: 457461.

53. Schuman BM, Beckman JW, Tedesco FJ, Griffin JW Jr, Assad RT: Complications of endoscopic injection sclerotherapy: a review. Am J Gastroenterol 1987; 82: 823-830.

54. Korula J, Chin K, Ko Y, Yamada S: Demonstration of two distinct subsets of gastric varices. Observations during a seven-year study of endoscopic sclerotherapy. Dig Dis Sci 1991; 36: 303-309.

55. Gimson AE, Westaby D, Williams R: Endoscopic sclerotherapy in the management of gastric variceal haemorrhage. J Hepatol 1991; 13: 274-378.

56. Jutabha R, Jensen DM, See J, Machicado G, Hirabayashi K: Randomized, controlled study of various agents for endoscopic injection sclerotherapy of bleeding canine gastric varices. Gastrointest Endosc 1995; 41: 206-211.

57. Oho K, Iwao T, Sumino M, Toyonaga A, Tanikawa $\mathrm{K}$ : Ethanolamine oleate versus butyl cyanoacrylate for bleeding gastric varices: a nonrandomized study. Endoscopy 1995; 27: 349-354.

58. Hashizume $\mathrm{M}$, Akahoshi $\mathrm{T}$, Tomikawa $\mathrm{M}$ : Management of gastric varices. J Gastroenterol Hepatol 2011; 26 (Suppl 1): 102-108.

59. Obara K, Sakamoto H, Kasukawa R: Prediction of the recurrence of esophageal varices based on portal vein pressure and oxygen tension in portal and peripheral blood. Gastroenterol Jpn 1991; 26: 707-711.

60. Hou MC, Lin HC, Kuo BI, Chen CH, Lee FY, Lee SD: Comparison of endoscopic variceal injection sclerotherapy and ligation for the treatment of esophageal variceal hemorrhage: a prospective randomized trial. Hepatology 1995; 21: 1517-1522.

61. Saeed ZA, Stiegmann GV, Ramirez FC, et al: 
Endoscopic variceal ligation is superior to combined ligation and sclerotherapy for esophageal varices: a multicenter prospective randomized trial Hepatology 1997; 25: 71-74.

62. Laine L, Stein C, Sharma V: Randomized comparison of ligation versus ligation plus sclerotherapy in patients with bleeding esophageal varices. Gastroenterology 1996; 110: 529-533.

63. Lo GH, Lai KH, Cheng JS, et al.: The additive effect of sclerotherapy to patients receiving repeated endoscopic variceal ligation: a prospective, randomized trial. Hepatology 1998; 28: 391-395.

64. Takase Y, Shibuya S, Chikamori F, Orii K, Iwasaki $\mathrm{Y}$ : Recurrence factors studied by percutaneous transhepatic portography before and after endoscopic sclerotherapy for esophageal varices. Hepatology 1990; 11: 348-352.

65. Yoshida H, Mamada Y, Taniai N, Tajiri T: New methods for the management of gastric varices. World J Gastroenterol 2006; 12: 5926-5931.

66. Yoshida H, Mamada Y, Taniai N, Tajiri T: New methods for the management of esophageal varices. World J Gastroenterol 2007; 13: 1641-1645.

67. Yoshida H, Mamada Y, Taniai N, et al.: Interactions between anti-ulcer drugs and non-steroidal antiinflammatory drugs in cirrhotic patients with bleeding esophagogastric varices. Hepatogastroenterology 2009; 56: 1366-1370.

68. Bernard B, Grange JD, Khac EN, Amiot X, Opolon P, Poynard T: Antibiotic prophylaxis for the prevention of bacterial infections in cirrhotic patients with gastrointestinal bleeding: a meta-analysis. Hepatology 1999; 29: 1655-1661.

69. Matsutani S, Maruyama H, Sato G, et al.: White ball appearance in endoscopic ligation of bleeding esophageal varices. Gastrointest Endosc 1998; 47: 254-256.

70. Garcia-Pagan JC, Bosch J: Endoscopic band ligation in the treatment of portal hypertension. Nat Clin Pract Gastroenterol Hepatol 2005; 2: 526-535.

71. Narahara Y, Kanazawa H, Kawamata H, et al.: A randomized clinical trial comparing transjugular intrahepatic portosystemic shunt with endoscopic sclerotherapy in the long-term management of patients with cirrhosis after recent variceal hemorrhage. Hepatol Res 2001; 21: 189-198.

72. D'Imperio N, Piemontese A, Baroncini D, et al. Evaluation of undiluted N-butyl-2-cyanoacrylate in the endoscopic treatment of upper gastrointestinal tract varices. Endoscopy 1996; 28: 239-243.

73. Lo GH, Lai KH, Cheng JS, Chen MH, Chiang HT: A prospective, randomized trial of butyl cyanoacrylate injection versus band ligation in the management of bleeding gastric varices. Hepatology 2001; 33: 10601064.

74. Kind R, Guglielmi A, Rodella L, et al.: Bucrylate treatment of bleeding gastric varices: 12 years' experience. Endoscopy 2000; 32: 512-519.

75. Huang YH, Yeh HZ, Chen GH, et al.: Endoscopic treatment of bleeding gastric varices by N-butyl-2cyanoacrylate (Histoacryl) injection: long-term efficacy and safety. Gastrointest Endosc 2000; 52: 160-167.

76. Akahoshi T, Hashizume M, Shimabukuro R, et al.: Long-term results of endoscopic Histoacryl injection sclerotherapy for gastric variceal bleeding: a 10-year experience. Surgery 2002; 131: S176-S181.

77. Soehendra N, Grimm H, Nam VC, Berger B: N-butyl2-cyanoacrylate: a supplement to endoscopic sclerotherapy. Endoscopy 1987; 19: 221-224.

78. Yamamoto M, Suzuki H: Endoscopic treatment for esophago-gastric varices, current status in Japan. Hepatogastroenterology 1997; 44: 637-646.

79. Shiha G, El-Sayed SS: Gastric variceal ligation: a new technique. Gastrointest Endosc 1999; 49: 437-441.

80. Savoye G, Hochain P, Riachi G, et al.: Early massive bleeding after endoscopic ligation for junctional varices. Endoscopy 1998; 30: S101.

81. Hashizume M, Kitano S, Sugimachi K, Sueishi K: Three-dimensional view of the vascular structure of the lower esophagus in clinical portal hypertension. Hepatology 1988; 8: 1482-1487.

82. Watanabe K, Kimura K, Matsutani S, Ohto M, Okuda $\mathrm{K}$ : Portal hemodynamics in patients with gastric varices. A study in 230 patients with esophageal and/or gastric varices using portal vein catheterization. Gastroenterology 1988; 95: 434-440.

83. de Franchis R: Evolving consensus in portal hypertension. Report of the Baveno IV consensus workshop on methodology of diagnosis and therapy in portal hypertension. J Hepatol 2005; 43: 167-176.

84. Sarin SK, Jain AK, Jain M, Gupta R: A randomized controlled trial of cyanoacrylate versus alcohol injection in patients with isolated fundic varices. Am J Gastroenterol 2002; 97: 1010-1015.

85. Tan PC, Hou MC, Lin HC, et al.: A randomized trial of endoscopic treatment of acute gastric variceal hemorrhage: N-butyl-2-cyanoacrylate injection versus band ligation. Hepatology 2006; 43: 690-697.

86. Lo GH, Liang HL, Chen WC, et al.: A prospective, randomized controlled trial of transjugular intrahepatic portosystemic shunt versus cyanoacrylate injection in the prevention of gastric variceal rebleeding. Endoscopy 2007; 39: 679-685.

87. Mishra SR, Chander Sharma B, Kumar A, Sarin SK: Endoscopic cyanoacrylate injection versus betablocker for secondary prophylaxis of gastric variceal bleed: a randomised controlled trial. Gut 2010; 59: 729-735.

88. Yoshida T, Harada T, Shigemitsu T, Takeo Y, Miyazaki S, Okita K: Endoscopic management of gastric varices using a detachable snare and simultaneous endoscopic sclerotherapy and O-ring ligation. J Gastroenterol Hepatol 1999; 14: 730-735.

89. Nishikawa Y, Hosokawa Y, Doi T, et al: Simultaneous combination of endoscopic sclerotherapy and endoscopic ligation for esophageal varices. Gastrointest Endosc 1995; 42: 358-360.

90. Ninoi $T$, Nishida $N$, Kaminou $T$, et al.: Balloonoccluded retrograde transvenous obliteration of gastric varices with gastrorenal shunt: long-term follow-up in 78 patients. AJR Am J Roentgenol 2005; 184: $1340-1346$.

91. Akahoshi T, Hashizume M, Tomikawa M, et al.: Long-term results of balloon-occluded retrograde transvenous obliteration for gastric variceal bleeding and risky gastric varices: a 10 -year experience. J Gastroenterol Hepatol 2008; 23: 1702-1709.

92. Chikamori F, Kuniyoshi N, Shibuya S, Takase Y: Eight years of experience with transjugular 
retrograde obliteration for gastric varices with gastrorenal shunts. Surgery 2001; 129: 414-420.

93. Hirota $\mathrm{S}$, Ichikawa $\mathrm{S}$, Matsumoto $\mathrm{S}$, Motohara $\mathrm{T}$, Fukuda T, Yoshikawa T: Interventional radiologic treatment for idiopathic portal hypertension. Cardiovasc Intervent Radiol 1999; 22: 311-314.

94. Chikamori F, Kuniyoshi N, Kawashima T, Shibuya S, Takase Y: Combination treatment of partial splenic embolization, endoscopic embolization and transjugular retrograde obliteration for complicated gastroesophageal varices. Hepatogastroenterology 2004; 51: 1506-1509.

95. Chau TN, Patch D, Chan YW, Nagral A, Dick R, Burroughs AK: "Salvage" transjugular intrahepatic portosystemic shunts: gastric fundal compared with esophageal variceal bleeding. Gastroenterology 1998; 114: 981-987.

96. Henderson JM, Boyer TD, Kutner MH, et al: Distal splenorenal shunt versus transjugular intrahepatic portal systematic shunt for variceal bleeding: a randomized trial. Gastroenterology 2006; 130: 16431651.

97. Boyer TD, Henderson JM, Heerey AM, et al: Cost of preventing variceal rebleeding with transjugular intrahepatic portal systemic shunt and distal splenorenal shunt. J Hepatol 2008; 48: 407-414.

(Received, August 27, 2011)

(Accepted, October 31, 2011) 